\title{
PENENTUAN NILAI KONSTANTA JOULE MENGGUNAKAN ALAT PRAKTIKUM KALORIMETER ALIRAN DILENGKAPI DENGAN SENSOR SUHU
}

\author{
Dede Muchyiddin $^{\text {a) }}$, Esmar Budi ${ }^{\text {b) }}$, Sunaryo ${ }^{\text {c) }}$ \\ Program Studi Pendidikan Fisika, FMIPA, Universitas Negeri Jakarta, Jakarta, 13220, Indonesia

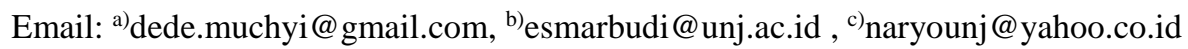

\begin{abstract}
Abstrak
Telah dilakukan pengembangan alat kalorimeter aliran dengan sensor suhu untuk menentukan nilai konstanta joule. Penelitian ini bertujuan untuk menghasilkan alat praktikum yang layak digunakan di laboratorium fisika dasar FMIPA UNJ. Metode penelitian yang digunakan adalah research and development $(\mathrm{RnD})$ menggunakan model ADDIE (Analysis-Design-Development-Implementation-Evaluation). Dalam pengembangannya penelitian ini dilakukan di laboratorium fisika dasar FMIPA UNJ. Hasil validasi oleh ahli materi dan ahli media menghasilkan nilai $94.23 \%$ dan $81.67 \%$ yang termasuk dalam kategori sangat layak. Kemudian hasil uji coba alat memperoleh rata-rata nilai konstanta Joule 3.995 dengan kesalahan relatif 5\%. Dengan demikian alat ini layak digunakan sebagai media praktikum di laboratorium fisika dasar FMIPA UNJ.
\end{abstract}

Kata kunci : Kalorimeter aliran, Konstanta Joule, Sensor Suhu

\begin{abstract}
Has developed a flow calorimeter tool with a temperature sensor to determine the Joule constant. This study aims to produce a practical tool that are feasible to be used in basic physics laboratory in FMIPA UNJ. The method used is research and development $(\mathrm{RnD})$ with ADDIE (Analysis-Design-Development-ImplementationEvaluation) model. In its development, this research was carried out in the basic physics laboratory of FMIPA UNJ. The results of the validation by material experts and media experts produced a value of $94.23 \%$ and $81.67 \%$ included in the very feasible category. Then the test results of this tool get the average Joule constant value of 3.955 with 5\% relative error. Thus, this tool is suitable to be used as a practicum tool in the basic physics laboratory of FMIPA UNJ.
\end{abstract}

Keywords : Flow Calorimeter, Joule Constant, Temperature Sensor

\section{PENDAHULUAN}

Dalam setiap proses, energi selalu berubah dari satu bentuk ke bentuk lainnya, hal ini dinamakan konversi energi [1]. Salah satu contoh konversi energi adalah energi listrik berubah menjadi energi panas (kalor). Dalam proses konversi energi listrik ke energi panas tidak semua energi listrik yang 
diberikan diubah menjadi energi kalor, terdapat suatu besaran yang mempengaruhinya. Besaran tersebut disebut konstanta Joule, nilainya adalah 1 kalori $=4,186$ Joule [2]. Bilangan 4,186 merupakan nilai kesetaraan antara kalori dan Joule.

Praktikum merupakan bagian penting dalam pembelajaran sains. Sejumlah penelitian menunjukan bahwa praktikum bermanfaat untuk meningkatkan kognitif, afektif dan psikomotor peserta didik [3]. Dalam fisika, praktikum dilakukan untuk membuktikan suatu teori atau menggunakan suatu teori untuk menghitung suatu besaran fisika [4]. Nilai konstanta Joule berdasarkan literatur dapat kita buktikan dengan melakukan kegiatan praktikum. Agar percobaan yang dilakukan menghasilkan nilai yang akurat, maka alat praktikum tersebut haruslah memadai.

Dalam mata kuliah praktikum fisika dasar di Universitas Negeri Jakarta terdapat praktikum untuk menentukan nilai konstanta Joule. Praktikum ini menggunakan sebuah alat yang disebut kalorimeter aliran. Prinsip kerja alat ini ialah dengan mengalirkan air secara terus menerus ke dalam sebuah tabung kaca yang berisi elemen pemanas dari salah satu ujungnya dan mengeluarkan air tersebut pada ujung yang lain. Elemen pemanas ini dialiri listrik sehingga menyebabkan perbedaan suhu pada kedua ujung tabung kalorimeter [5]. Namun kalorimeter yang ada saat ini belum memadai dengan masih digunakannya termometer konvensional, maka dari itu penelitian kali ini akan mengubah termometer konvensional menjadi sensor suhu yang akan menampilkan data secara digital sehingga hasil yang didapat lebih akurat.

\section{METODE}

Metode Penelitian yang digunakan adalah metode penelitian pengembangan (Research and Development $/ R \& D)$. Sugiono menyatakan bahwa metode ini digunakan untuk menghasilkan produk tertentu dan menguji keefektifan produk tersebut [6]. Produk yang dikembangkan yaitu berupa alat praktikum kalorimeter aliran yang dilengkapi dengan sensor suhu. Penelitian ini mengunakan model ADDIE (Analysis, Design, Development, Implementation, and Evaluation). Dalam pengembangannya, penelitian ini dilakukan di laboratorium media FMIPA UNJ dan diuji cobakan kepada mahasiswa prodi pendidikan fisika.

\section{HASIL DAN PEMBAHASAN}

\section{Desain Rancangan Alat}

Kalorimeter aliran yang akan dibuat berbahan dasar kaca dengan bentuk silinder atau tabung dengan diameter $5 \mathrm{~cm}$ dan panjang sekitar $50 \mathrm{~cm}$. Ditengah dari silinder tersebut akan dipasangkan heater (pemanas) yang akan memanaskan air dalam kalorimeter. Di sisi kanan dan kiri kalorimeter terdapat lubang yang berfungsi sebagai tempat keluar dan masuknya air. Di sisi kanan dan kiri tersebut juga akan dipasangkan sensor suhu LM 35 yang akan mendeteksi seberapa besar suhu air didalamnya. Sensor tersebut juga dihubungkan dengan display yang akan menampilkan suhu secara digital, sehingga suhu yang terukur akan jauh lebih akurat dibandingkan dengan termometer biasa. Komponen alat ini terdiri dari tabung kalorimeter, elemen pemanas, sensor suhu dengan display, serta alas kayu. Di bawah ini adalah hasil desain tampilan alat praktikum kalorimeter aliran yang dibuat menggunakan aplikasi paint $3 D$. 


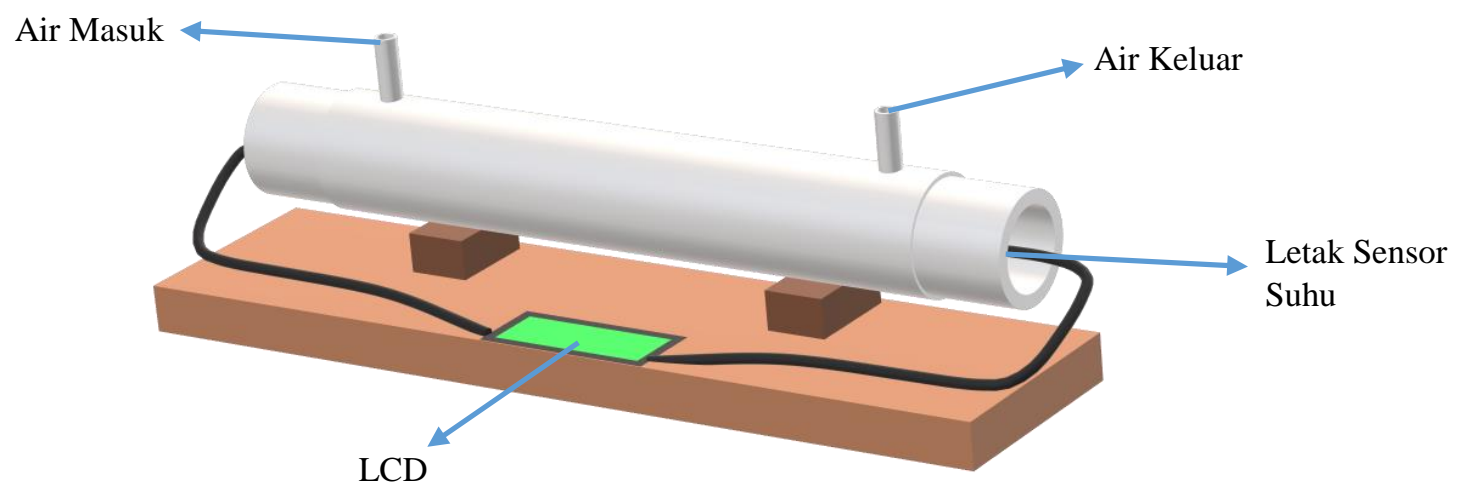

GAMBAR 1. Desain kalorimeter yang dilengkapi sensor suhu

\section{Hasil Rancangan Alat}

Berikut ini adalah hasil realisasi dari komponen alat kalorimeter aliran :

a) Tabung Kalorimeter

Komponen utama dalam alat ini adalah tabung kalorimeter yang terbuat dari bahan kaca dan bentuk yang dibuat sedemikian rupa. Tabung ini memiliki diameter $5 \mathrm{~cm}$ dengan panjang total $46 \mathrm{~cm}$. Tabung ini memiliki 2 buah lubang dekat ujungnya sebagai tempat masuk dan keluarnya air. Dibagian ujung-ujung tabung akan diletakkan sensor suhu untuk mengukur perbedaan suhu di kedua ujung tabung.

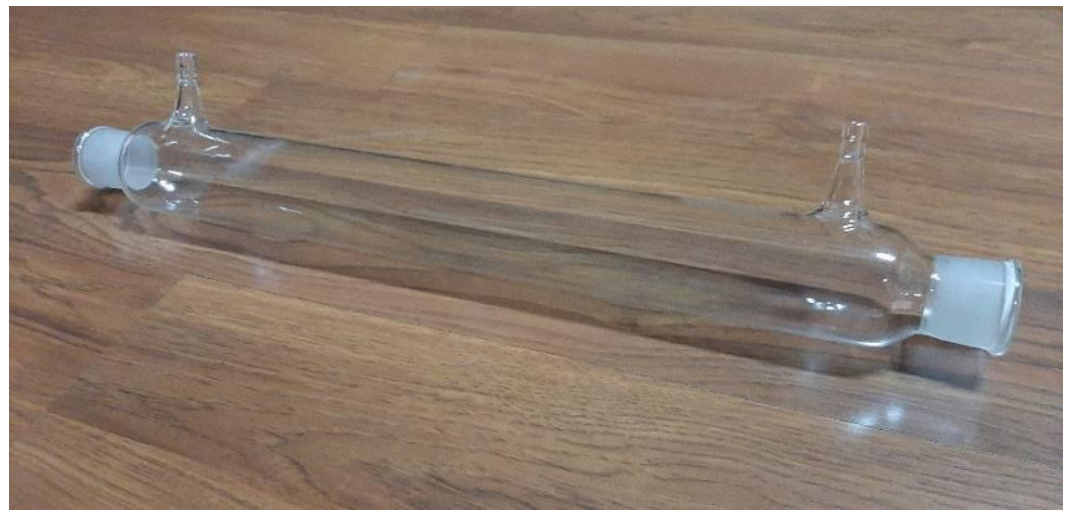

GAMBAR 2. Tabung calorimeter

b) Elemen pemanas (Heater)

Komponen selanjutnya adalah elemen pemanas (heater) dengan panjang 20 inci dan diameter sekitar 1,5 cm. Heater ini memiliki spesifikasi 220V/240Watt. Heater ini tersusun dari gulungan kawat yang dimasukkan kedalam tabung kaca. Dikedua ujung heater ini terdapat karet yang berfungsi menutup tabung kaca dan sekaligus sebagai isolator agar heater ini dapat dipegang. Ketika proses praktikum, heater ini akan dihubungkan dengan power supply sebagai sumber energinya. 


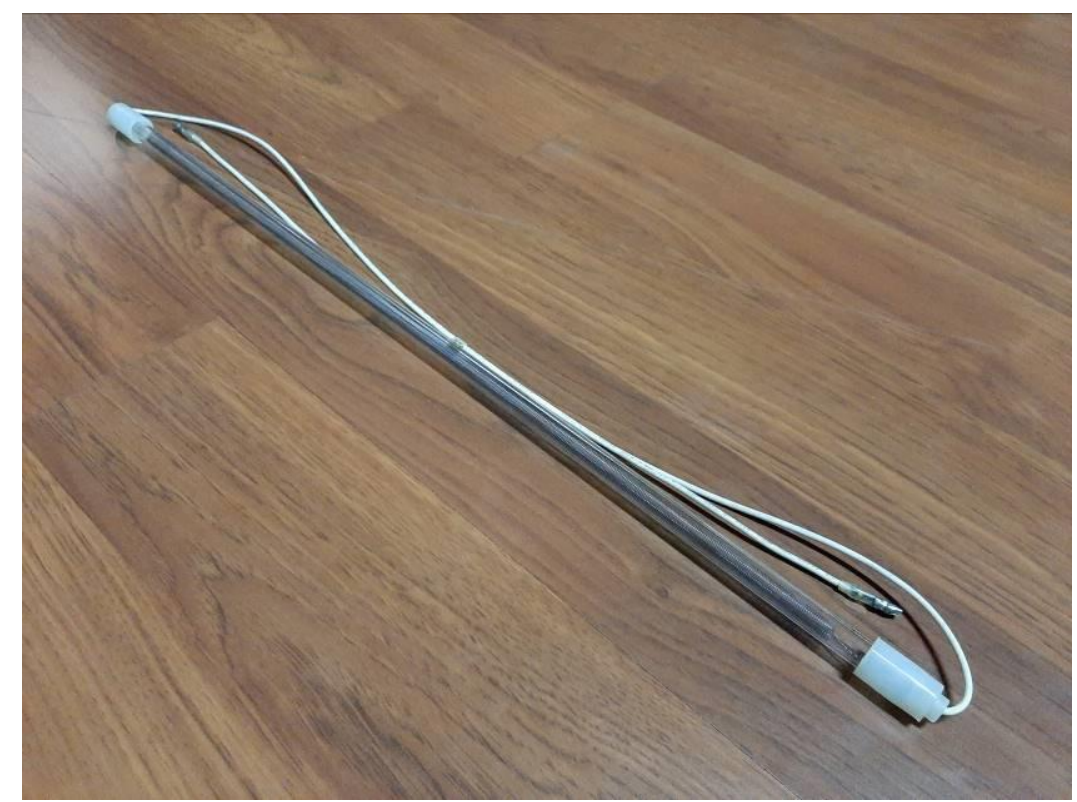

GAMBAR 3. Elemen pemanas (Heater)

c) Sensor Suhu

Komponen ini merupakan komponen paling penting dalam pengembangan alat kalorimeter ini. Sensor suhu yang digunakan ialah sensor suhu LM-35. Alasan pemilihan sensor ini adalah karena sensor LM-35 memiliki tingkat akurasi yang tinggi dan perancangannya lebih mudah jika dibandingkan dengan sensor suhu yang lain. LM-35 juga menghasilkan keluaran impedansi yang rendah dengan linieritas yang tinggi, sehingga dapat dengan mudah dihubungkan dengan rangkaian kendali khusus serta tidak memerlukan penyetelan lanjutan. LM-35 juga tidak mudah panas, self-heating dari sensor ini kurang dari $0,5^{\circ} \mathrm{C}$ pada suhu 25 ${ }^{\circ} \mathrm{C}$ [7]. Sensor suhu ini memiliki ketelitian $0,1^{\circ} \mathrm{C}$ yang tentunya lebih akurat dibandingkan termometer konvensional.

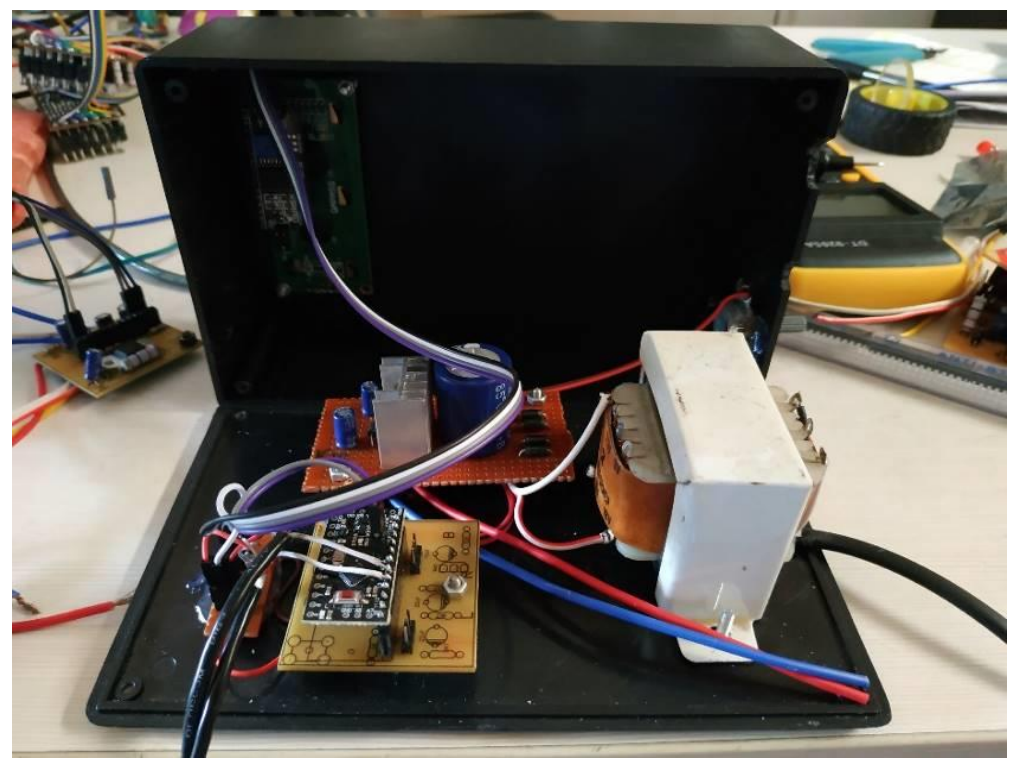

GAMBAR 4. Bagian dalam sensor suhu 


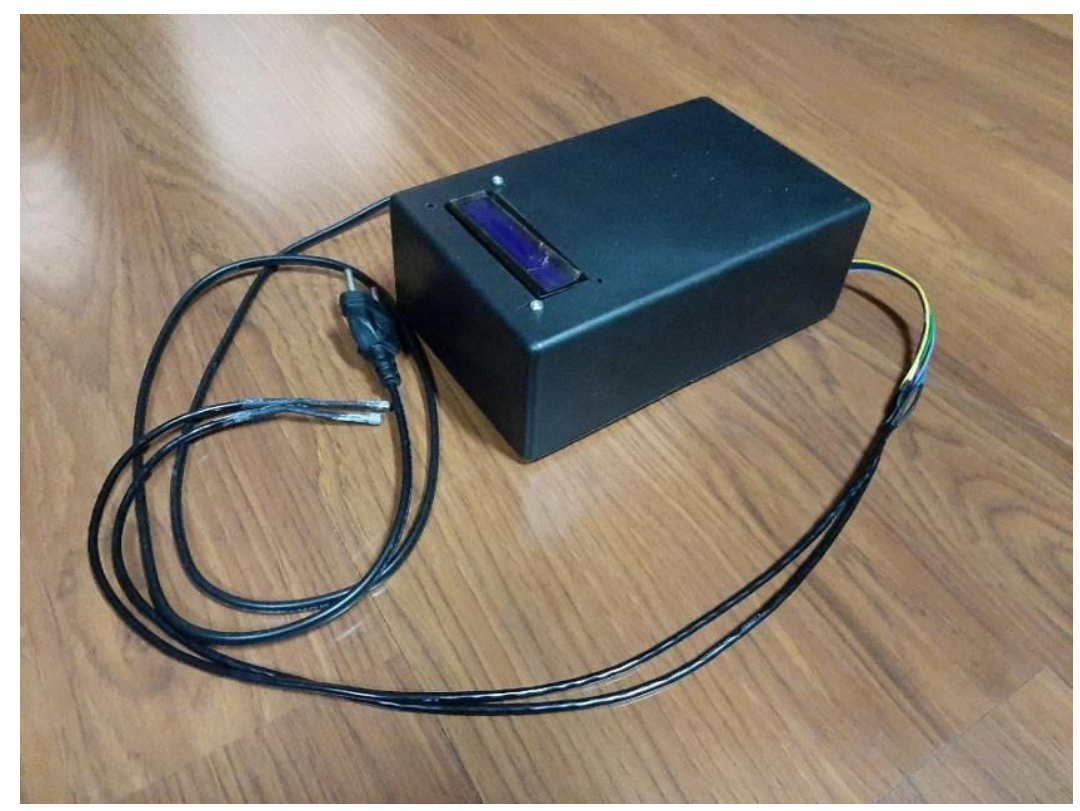

GAMBAR 5. Kotak rangkaian sensor suhu

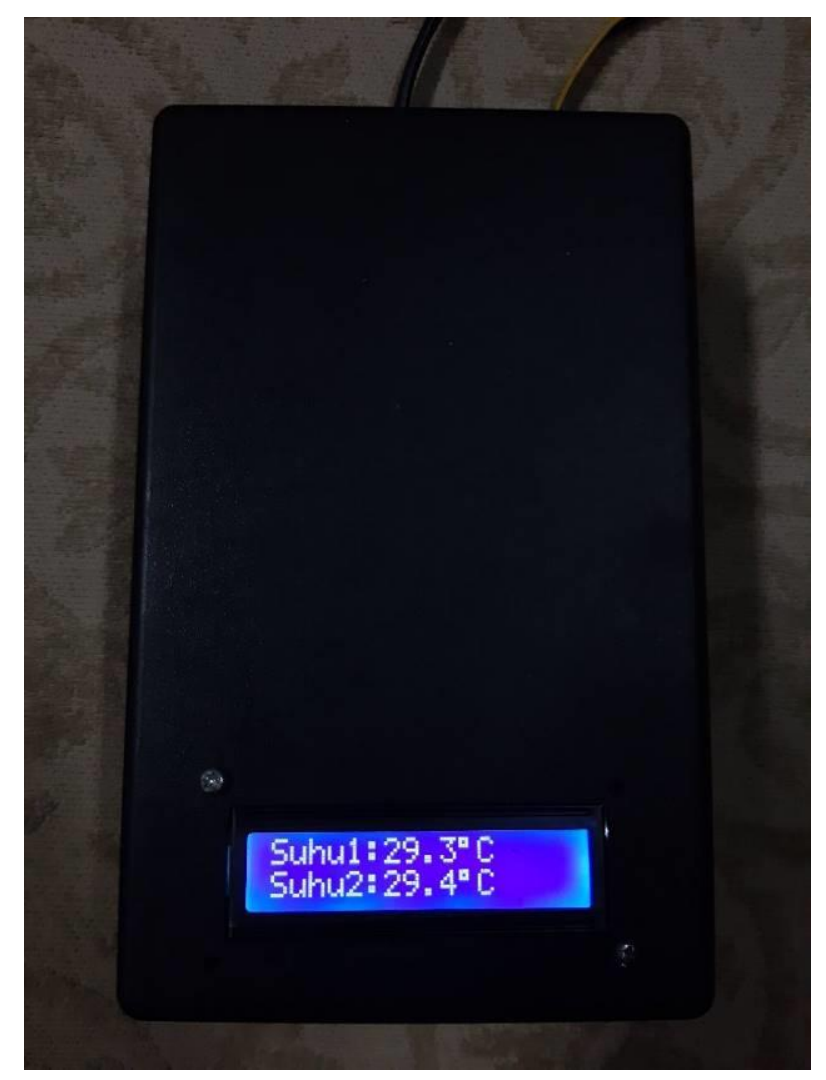

GAMBAR 6. Sensor suhu menunjukkan nilai suhu benda yang diukur 


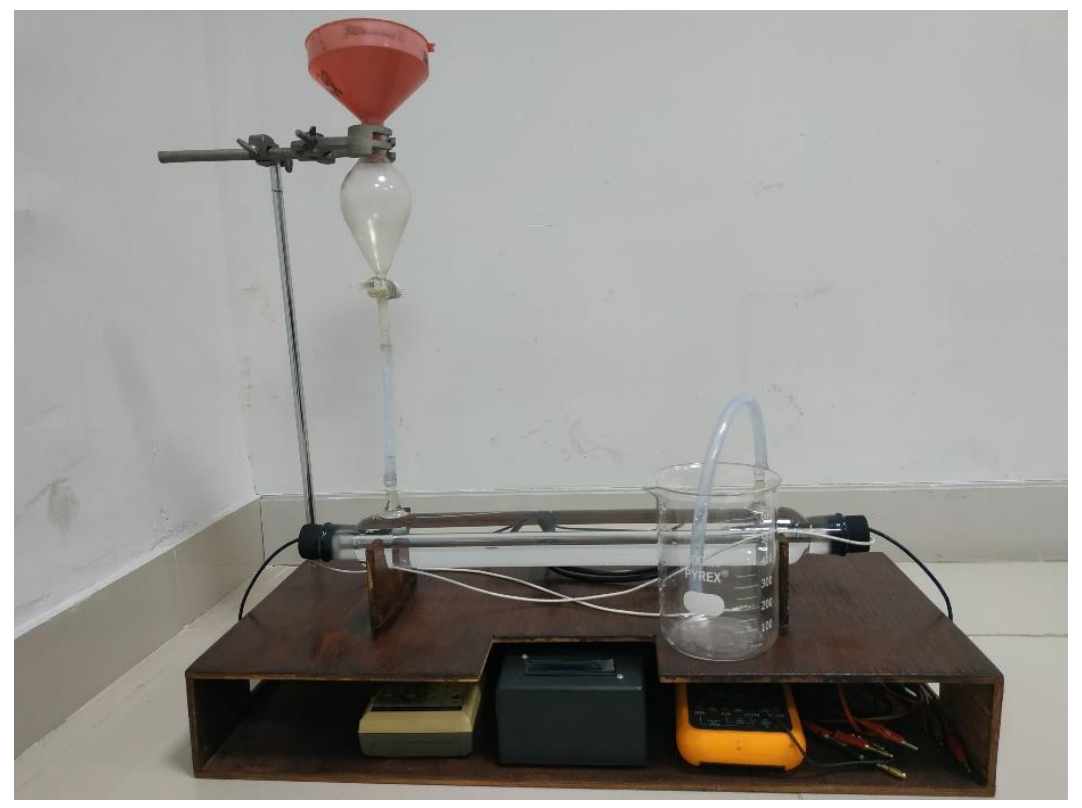

GAMBAR 7. Komponen alat kalorimeter aliran setelah disatukan

\section{Hasil Uji Coba Alat}

\begin{tabular}{|c|c|c|c|c|c|c|c|c|c|c|}
\hline \multirow[b]{2}{*}{ No. } & \multirow[b]{2}{*}{$\begin{array}{c}\text { Tegangan } \\
\text { (V) }\end{array}$} & \multirow[b]{2}{*}{$\begin{array}{l}\text { Arus } \\
\text { (A) }\end{array}$} & \multirow[b]{2}{*}{$\begin{array}{c}\text { Waktu } \\
\text { (s) }\end{array}$} & \multirow[b]{2}{*}{$\begin{array}{c}\text { Massa } \\
\text { (gr) }\end{array}$} & \multirow{2}{*}{$\begin{array}{c}\text { Kalor } \\
\text { Jenis Air } \\
(\mathbf{K a l} / \mathbf{g} \\
\left.{ }^{\circ} \mathbf{C}\right)\end{array}$} & \multirow[b]{2}{*}{$\begin{array}{c}\Delta \mathbf{T} \\
\left({ }^{\circ} \mathbf{C}\right)\end{array}$} & \multirow[b]{2}{*}{$\begin{array}{c}\text { W } \\
\text { (Joule) }\end{array}$} & \multirow[b]{2}{*}{$\begin{array}{c}\mathbf{Q} \\
\text { (Kalori) }\end{array}$} & \multirow[b]{2}{*}{$\underset{(\mathbf{J} / \mathbf{K} \text { al) }}{\mathbf{J}}$} & \multirow[b]{2}{*}{ KSR } \\
\hline & & & & & & & & & & \\
\hline 1 & 40.3 & 0.131 & 30 & 131 & 1 & 0.3 & 158.38 & 39.3 & 4.030 & $4 \%$ \\
\hline 2 & 50.5 & 0.163 & 30 & 124 & 1 & 0.5 & 246.95 & 62.0 & 3.983 & $5 \%$ \\
\hline 3 & 60.7 & 0.193 & 30 & 145 & 1 & 0.6 & 351.45 & 87.0 & 4.040 & $3 \%$ \\
\hline 4 & 70.2 & 0.225 & 30 & 115 & 1 & 1.0 & 473.85 & 115.0 & 4.120 & $2 \%$ \\
\hline 5 & 80.5 & 0.255 & 30 & 120 & 1 & 1.3 & 615.83 & 156.0 & 3.948 & $6 \%$ \\
\hline 6 & 90.3 & 0.285 & 30 & 122 & 1 & 1.6 & 772.07 & 195.2 & 3.955 & $6 \%$ \\
\hline 7 & 100.6 & 0.317 & 30 & 122 & 1 & 2.0 & 956.71 & 244.0 & 3.921 & $6 \%$ \\
\hline 8 & 110.2 & 0.346 & 30 & 136 & 1 & 2.1 & 1143.88 & 285.6 & 4.005 & $4 \%$ \\
\hline 9 & 120.3 & 0.378 & 30 & 148 & 1 & 2.3 & 1364.20 & 340.4 & 4.008 & $4 \%$ \\
\hline \multirow[t]{2}{*}{10} & 130.4 & 0.409 & 30 & 145 & 1 & 2.8 & 1600.01 & 406.0 & 3.941 & $6 \%$ \\
\hline & & & & & & & \multicolumn{2}{|c|}{ Rata-rata nilai $\mathrm{J}$} & 3.995 & $5 \%$ \\
\hline
\end{tabular}

TABEL 1. Hasil uji coba alat kalorimeter aliran dengan sensor suhu

TABEL 2. Hasil uji coba alat kalorimeter yang lama 


\begin{tabular}{ccccccccccc}
\hline No. & $\begin{array}{c}\text { Tegangan } \\
(\mathbf{V})\end{array}$ & $\begin{array}{c}\text { Arus } \\
(\mathbf{A})\end{array}$ & $\begin{array}{c}\text { Waktu } \\
(\mathbf{s})\end{array}$ & $\begin{array}{c}\text { Massa } \\
(\mathbf{g r})\end{array}$ & $\begin{array}{c}\text { Kalor } \\
\mathbf{J e n i s} \mathbf{A i r} \\
\left(\mathbf{K a l} / \mathbf{g}^{\circ} \mathbf{C}\right)\end{array}$ & $\begin{array}{c}\Delta \mathbf{T} \\
\left({ }^{\circ} \mathbf{C}\right)\end{array}$ & $\begin{array}{c}\mathbf{W} \\
(\mathbf{J o u l e})\end{array}$ & $\begin{array}{c}\mathbf{Q} \\
(\text { Kalori })\end{array}$ & $\begin{array}{c}\mathbf{J} \\
(\mathbf{J} / \mathbf{K a l})\end{array}$ & $\mathbf{K S R}$ \\
\hline 1 & 2.06 & 0.522 & 30 & 120 & 1 & 1.0 & 32.26 & 120.0 & 0.269 & $94 \%$ \\
2 & 3.97 & 1.015 & 30 & 124 & 1 & 1.0 & 120.89 & 124.0 & 0.975 & $77 \%$ \\
3 & 6.15 & 1.554 & 30 & 125 & 1 & 1.0 & 286.71 & 125.0 & 2.294 & $45 \%$ \\
4 & 7.97 & 2.045 & 30 & 121 & 1 & 2.0 & 488.96 & 242.0 & 2.020 & $52 \%$ \\
5 & 9.83 & 2.515 & 30 & 120 & 1 & 2.0 & 741.67 & 240.0 & 3.090 & $26 \%$ \\
6 & 12.09 & 3.087 & 30 & 122 & 1 & 3.0 & 1119.65 & 366.0 & 3.059 & $27 \%$ \\
7 & 14.02 & 3.517 & 30 & 122 & 1 & 4.0 & 1479.25 & 488.0 & 3.031 & $28 \%$ \\
8 & 16.37 & 4.108 & 30 & 127 & 1 & 5.0 & 2017.44 & 635.0 & 3.177 & $24 \%$ \\
9 & 17.87 & 4.514 & 30 & 126 & 1 & 5.0 & 2419.96 & 630.0 & 3.841 & $8 \%$ \\
10 & 19.58 & 5.024 & 30 & 128 & 1 & 6.0 & 2951.10 & 768.0 & 3.843 & $8 \%$ \\
\hline & & & & & & & Rata-rata nilai J & 2.560 & $39 \%$ \\
\hline
\end{tabular}

\section{Pembahasan}

Dari hasil percobaan yang telah dilakukan menunjukkan bahwa alat ini sudah cukup baik dalam memperoleh nilai konstanta Joule. Lebih baik dibandingkan dengan alat kalorimeter yang lama yang menggunakan termometer konvensional sebagai pengukur suhunya. Dengan diubahnya termometer konvensional yang memiliki ketelitian $1{ }^{\circ} \mathrm{C}$ menjadi sensor suhu yang memiliki ketelitian $0.1^{\circ} \mathrm{C}$ terjadi peningkatan akurasi yang cukup signifikan. Nilai suhu yang terukur lebih akurat sehingga nilai konstanta Joule yang dihasilkan pun lebih mendekati nilai yang terdapat dalam teori.

Kesetaraan energi listrik dan panas merupakan perbandingan antara energi listrik dengan energi panas. Energi listrik yang diberikan dikonversi menjadi energi panas. Namun dalam percobaan ini tidak semua energi listrik yang disalurkan oleh heater diserap seluruhnya menjadi energi panas oleh air. Ada sebagian energi yang hilang, baik itu diserap oleh tabung ataupun oleh udara sekitar tabung. Maka dari itu hasil yang diperoleh belum mendekati nilai yang terdapat dalam literatur namun masih dalam tingkat yang wajar yaitu dengan kesalahan relatif $\pm 5 \%$.

\section{SIMPULAN}

Pada penelitian ini telah dihasilkan alat praktikum kalorimeter aliran yang dilengkapi dengan sensor suhu yang dapat digunakan untuk membuktikan nilai konstanta Joule. Pengembangan ini dilakukan untuk memudahkan dalam pembacaan data suhu, serta untuk mendapatkan hasil yang lebih akurat.

\section{UCAPAN TERIMA KASIH}

Penulis mengucapkan terima kasih kepada berbagai pihak yang telah membantu dalam penulisan makalah ini. Serta kepada kedua orang tua yang selalu memberi dukungan, baik dari segi moril maupun materil.

\section{REFERENSI}


[1] Y. Demirel, Energy, Green Energy and Technology, Switzerland: Springer International, 2016.

[2] R. A. Serway dan J. W. Jewett, Fisika Untuk Sains dan Teknik, Jakarta: Salemba Teknika, 2010 .

[3] Millar dan Abrahams, "Does practical work really work? A study on the effectiveness of practical work as a teaching and learning method in school science," in International Journal of Science Education No.14, vol. 30, 2008, pp. 1945-1969.

[4] H. N. Safitri, Masturi dan S. S. Edie, "Pengembangan Alat Praktikum Kalorimeter Bom pada Pokok Bahasan Kalor," in Unnes Physics Education Journal, vol. 1, 2018, pp. $42-48$.

[5] Tim Dosen Fisika Dasar, Panduan Praktikum Fisika Dasar 1, Jakarta: UNJ, 2014.

[6] Sugiyono, Metode Penelitian \& Pengembangan Research and Development, Bandung: Alfabeta, 2015.

[7] S. Karim, Sensor \& Aktuator Untuk SMK/MAK Kelas XI, Malang: Kementerian Pendidikan dan Kebudayaan, 2013. 